Rev. Bras. Saúde Prod. Anim., Salvador, v.15, n.4, p.928-936 out./dez., 2014 http://www.rbspa.ufba.br ISSN 15199940

\title{
Adaptabilidade de caprinos Sannen e Marota mantidos em clima tropical semiúmido
}

\author{
Adaptability of goats kept in Saanen and Marota semi moist tropicalclimate
}

\author{
SANTOS, Francisco Sérgio Medeiros dos ${ }^{1}$; PIRES, João Eduardo Pinto ${ }^{2}$; PEREIRA, \\ Alécio Matos ${ }^{2}$; AZEVEDO, Danielle Maria Machado Ribeiro ${ }^{3}$; ROCHA, Raimundo \\ Rômulo Costa ${ }^{1}$; CARDOSO, Francimarne Sousa ${ }^{2}$; ARAUJO, Adriana Mello ${ }^{3}$; \\ MURATORI, Maria Christina Sanches ${ }^{1}$; COSTA, Amilton Paulo Raposo ${ }^{1 *}$
}

\footnotetext{
${ }^{1}$ Universidade Federal do Piauí, Departamento de Morfofisiologia Veterinária Teresina, Piauí, Brasil.

${ }^{2}$ Universidade Federal do Piauí, Programa de Pós-Graduação em Biotecnologia, Bom Jesus, Piauí, Brasil

${ }^{3}$ Embrapa, Teresina, Piauí. Brasil.

*Endereço para correspondência: amilfox@uol.com.br
}

\section{RESUMO}

Objetivou-se com este trabalho avaliar os parâmetros ambientais e os parâmetros e fisiológicos dos caprinos Saanen e Marota na cidade de Teresina, estado do Piauí, Brasil, nos períodos chuvosos e secos, durante os meses de abril a novembro. Utilizaram-se fềmeas caprinas adultas Saanen $(\mathrm{n}=7)$ e Marota $(\mathrm{n}=7)$, clinicamente saudáveis, de mesmas faixas etárias e submetidas às mesmas condições de manejo. Os índices fisiológicos foram a frequência cardíaca (FC), frequência respiratória (FR) e temperatura retal (TR) nos horários de 7-8, 10-11, 14-15 e 1718horas. Os índices ambientais analisados foram a temperatura ambiente, umidade relativa do ar,temperatura de globo negro e índices de temperatura e umidade. Os resultados dos parâmetros ambientais mostram que o período seco é mais estressante que o chuvoso e que o turno da tarde é mais estressante que o da manhã e, dentre os esses parâmetros, observa-se que a umidade relativa do ar tem comportamento inverso ao da temperatura do ar, temperatura de globo negro e índices de temperatura e umidade, mostrando maiores valores no período chuvoso e no turno da manhã. Quanto aos parâmetros fisiológicos dos animais, observou-se que todos os animais conseguiram manter a temperatura retal dentro dos limites normais, e que a frequência respiratória foi $\mathrm{o}$ indicador de estresse mais sensível, mostrando que os animais da raça Marota apresentaram menores valores e mais próximos da normalidade, indicando maior adaptabilidade em relação aos da raça Saanen

Palavras-chave: adaptação, bioclimatologia, estresse térmico, parâmetros físiológicos

\section{SUMMARY}

The study aimed to assess the environmental parameters and physiological parameters and Saanen goats and Marota in Teresina, Piauí State, Brazil, in the rainy and dry periods during the months from april to november. We used adult female Saanen goats $(n=7)$ and Marota $(n=7)$, clinically healthy, the same age group and subject to the same management conditions. The physiological indices were heart rate (HR), respiratory rate (RR) and rectal temperature (RT) in schedules 7-8, 10-11, 1415 and 17-18 hours. The environmental indices analyzed were room temperature, relative humidity, black globe temperature index and temperature and humidity index. The results of the environmental parameters show that the dry period is more stressful than the rainy and the afternoon shift is more stressful than the morning and among these parameters, it is observed that the relative humidity has the opposite behavior of the temperature air, temperature and black globe temperature and humidity index, showing higher values in the rainy season and in the morning shift. Regarding the physiological parameters of the animals, it was observed that all animals were able to maintain rectal temperature within normal limits and the respiratory rate was the most sensitive indicator of stress, showing that the animals Marota race had lower values and more close to normal, indicating greater adaptability in relation to Saanen.

Keywords: adaptation, bioclimatology, heat stress, physiological parameters 
Rev. Bras. Saúde Prod. Anim., Salvador, v.15, n.4, p.928-936 out./dez., 2014 http://www.rbspa.ufba.br ISSN 15199940

\section{INTRODUÇÃO}

Os caprinos introduzidos no nordeste brasileiro a partir da colonização foram criados de forma extensiva, passando assim por processo de adaptação às condições impostas pelo meio, processos esses que estão associados à perda de diversidade genética nos estágios iniciais, bem como a fixação de algumas características, como as causadas pela ação do clima, parasitas endêmicos, doenças e nutrição, fato que resultou em adaptabilidade às condições edafoclimáticas do semiárido, sendo aliados à agricultura familiar. Embora importante, o patrimônio genético está ameaçado de desaparecimento, devido à introdução de raças exóticas com a justificativa de melhorar os índices de desempenho dos animais da região, entretanto, as consequências desse processo a perda das características peculiares que poderão não ser mais recuperadas (XIMENES, 2009).

Diante disso, o estudo dos índices bioclimáticos tem por objetivo expressar o conforto que as raças Saanen e Marota possuem em clima tropical semiúmido. Essa avaliação depende de fatores como umidade relativa do ar, intensidade do vento, precipitações e radiação térmica. Os resultados possibilitam uma avaliação mais precisa da situação do ambiente e a comparação zootécnica entre os animais (ÁVILA et al., 2013).

Os parâmetros fisiológicos que melhor avaliam o estresse térmico para espécie caprina são frequências respiratória, cardíaca e temperatura retal (MARTINS JUNIOR et al, 2007a; SANTOS et al., 2005). Entretanto, os mesmos autores salientam que alguns índices físicos tais como índice de temperatura e umidade (ITU) e de temperatura do globo e umidade (ITGU), também têm sido utilizados com objetivo de caracterizar ou quantificar as faixas de conforto térmico para as diferentes espécies animais, em uma única variável que associa esses elementos climáticos. Em associação a elevação desses índices em Teresina, Piauí, Rocha et al, (2012), mostraram elevação da frequência respiratória como principal indicativo de estresse térmico. Segundo Santos et al. (2005) e Souza et al. (2005), a zona de conforto para ovinos deva situar-se entre 20 e $30^{\circ} \mathrm{C}$ e a umidade relativa do ar entre 60 e $70 \%$.

Portanto, objetivou-se comparar a adaptabilidade dos caprinos Saanen e Marota mantidas em clima tropical semiúmido, nos períodos chuvoso e seco, avaliando os parâmetros fisiológicos e ambientais.

\section{MATERIAL E MÉTODOS}

O trabalho foi desenvolvido nas instalações da Embrapa Meio-Norte, localizada no município de Teresina, Piauí, nos períodos chuvoso (abril a maio) e seco (outubro a novembro). Foram utilizados 14 caprinos, fêmeas, adultas (um a dois anos), vazias, sendo sete do grupo racial Marota e sete da raça Saanen, com média de peso respectivamente, de 22,07 e $28,06 \mathrm{~kg}$, clinicamente sadias e submetidas aos mesmos procedimentos de manejo à pasto.

Os parâmetros fisiológicos frequência respiratória (FR), frequência cardíaca (FC) e temperatura retal (TR) foram aferidos, nesta ordem, a fim de diminuir a influência do estresse de contenção física, com os animais à sombra do aprisco, nos seguintes horários: 7-8h, 10-11h, 14-15h e 17-18h, uma vez a cada quinze dias, sendo realizadas quatro coletas no período chuvoso e quatro no período seco. 
A FR, em movimentos por minuto, foi obtida por observação dos movimentos do flanco direito do animal, durante um minuto, mantendo-se o observador a uma distância de dois metros do animal pelo período de um minuto. A FC, em batimentos por minuto, foi obtida com a utilização de um estetoscópio posicionado entre o terceiro e quarto espaço intercostal, próximo à articulação costocondral, durante um minuto. A TR, em ${ }^{\circ} \mathrm{C}$, foi obtida por meio de termômetro digital inserido no reto do animal até o disparo do sonorizador.

A temperatura ambiente (TA) e umidade relativa do ar (UR) foram obtidas com auxílio de termohigrômetro (Incoterm, Porto Alegre, Brasil) e a temperatura de globo negro (TGN), através de globotermômetro (termômetro Inconterm 0 a $100^{\circ} \mathrm{C}$ inserido em um globo negro de $150 \mathrm{~mm}$ de diâmetro), instalados à altura de $55 \mathrm{~cm}$ do solo, que corresponde à altura média aproximada dos animais.

A partir da TA, UR e TGN foram calculados os índices: ITU - índice de temperatura e umidade e ITGU - índice de temperatura de globo e umidade (SILVA et al, 2005), calculados pelas fórmulas detalhadas a seguir:

ITU $=0,72\left(\mathrm{~Tb}_{\mathrm{s}}+\mathrm{Tb}_{\mathrm{u}}\right)+40,6$, onde $\mathrm{Tb}_{\mathrm{s}}$ é a temperatura do bulbo seco, em graus ${ }^{\circ} \mathrm{C}$ e Tbu a temperatura do bulbo úmido, ${ }^{\circ} \mathrm{C}$. ITGU $=0,7 \mathrm{Tbu}+0,3 \mathrm{Tgn}$, onde Tbu é temperatura do bulbo úmido não exposto diretamente à radiação solar, e Tgn temperatura globo negro, dados em ${ }^{\circ} \mathrm{C}$.

$\mathrm{O}$ delineamento estatístico utilizado foi o inteiramente ao acaso em esquema fatorial 2X2 (duas raças e dois períodos), com sete repetições, utilizando-se o programa estatístico SAS (SAS Institute, 1997). O teste estatístico para comparação de médias foi o $\mathrm{SNK}$, a $5 \%$ de probabilidade.

\section{RESULTADOS E DISCUSSÃO}

Os valores das variáveis ambientais estudadas estão apresentados na Tabela 1 , na qual se observa que a temperatura do ar apresentou diferença significativa $(\mathrm{P}<0,05)$ entre os diferentes horários da manhã e da tarde. Analisando-se a temperatura do ar pela manhã, nota-se que ela esteve dentro da zona de conforto térmico para caprinos, entre 20 e $30^{\circ} \mathrm{C}$, apenas no horário de $7-8$ horas, porém no período da tarde a temperatura esteve sempre acima dessa faixa, inclusive, ultrapassando a temperatura crítica efetiva superior, que é de $35^{\circ} \mathrm{C}$ (BAÊTA \& SOUSA, 1997). Esses valores foram semelhantes, aos encontrados por Souza et al. (2005) e por Martins Junior et al, (2007b), ou seja, valores dentro da zona de conforto térmico no início da manhã e desconforto no período da tarde. Considerando ainda a temperatura ambiente (TA) e avaliando também a umidade relativa do ar (UR), percebe-se que em todos os horários existe diferença significativa $(\mathrm{P}<0,05)$ entre os períodos chuvoso e seco.

Com vistas à TGN, observa-se no período chuvoso um valor significativamente crescente até às $15 \mathrm{~h}$, seguido de redução até o horário de 1718h. No período seco, o valor teve crescimento significativo $(\mathrm{p}<0,05)$ até as $14-15 \mathrm{~h}$ e manteve-se nesse patamar até as 17-18h. Assim sendo, a TGN mostra um comportamento semelhante ao da TA, na evolução ao longo do dia, porém com valores absolutos diferentes, devido à influência do calor recebido pelo globo negro, por radiação e da velocidade dos ventos incidindo sobre ele. Segundo Santos et al. (2005) a zona de conforto térmico relativa à TGN é considerada crítica quando acima de $35^{\circ} \mathrm{C}$ e esse valor só foi observado durante o período seco, a partir das 10 horas. 
Rev. Bras. Saúde Prod. Anim., Salvador, v.15, n.4, p.928-936 out./dez., 2014 http://www.rbspa.ufba.br ISSN 15199940

Essas temperaturas são superiores ao conforto térmico, o que pode ocasionar aumento no volume-minuto respiratório e na termólise evaporativa respiratória dos animais sob estresse, levando-os a perda de peso, redução no consumo de matéria seca, redução no peso corporal e duplicação do consumo de água (BRASIL et al, 2000).

Tabela 1. Médias das variáveis ambientais (VA) temperatura ambiente (TA), umidade relativa (UR) e temperatura de globo negro (TGN), tomadas nos períodos chuvoso (abril e maio) e seco (outubro e novembro), em diferentes horários, no momento da coleta dos parâmetros fisiológicos, na Embrapa Meio-Norte, município de Teresina, Piauí, em 2005

\begin{tabular}{|c|c|c|c|c|}
\hline \multirow{3}{*}{ VA } & \multicolumn{4}{|c|}{ Chuvoso } \\
\hline & \multicolumn{4}{|c|}{ Horário } \\
\hline & $7-8$ & $10-11$ & 14-15 & $17-18$ \\
\hline $\mathrm{TA}\left({ }^{\circ} \mathrm{C}\right)$ & $27,63 \pm 0,83^{\mathrm{Bc}}$ & $32,50 \pm 1,63^{\mathrm{Bb}}$ & $34,75 \pm 1,31^{\mathrm{Ba}}$ & $34,25 \pm 2,705^{\mathrm{Bb}}$ \\
\hline UR & $92,00 \pm 0,00^{\mathrm{Aa}}$ & $75,00 \pm 6,26^{\mathrm{Ac}}$ & $68,00 \pm 6,80^{\mathrm{Ad}}$ & $78,25 \pm 7,63^{\mathrm{Ab}}$ \\
\hline TGN & $26,87 \pm 0,90^{\mathrm{Bc}}$ & $32,50 \pm 1,83^{\mathrm{Bb}}$ & $34,25 \pm 0,84^{\mathrm{Ba}}$ & $32,00 \pm 2,27^{\mathrm{Bb}}$ \\
\hline \multirow{3}{*}{ VA } & \multicolumn{4}{|c|}{ Seco } \\
\hline & \multicolumn{4}{|c|}{ Horário } \\
\hline & $7-8$ & $10-11$ & 14-15 & $17-18$ \\
\hline $\mathrm{TA}\left({ }^{\circ} \mathrm{C}\right)$ & $32,02 \pm 3,72^{\mathrm{Ac}}$ & $35,02 \pm 0,45^{\mathrm{Ab}}$ & $37,55 \pm 1,02^{\mathrm{Aa}}$ & $37,55 \pm 1,02^{\mathrm{Aa}}$ \\
\hline UR & $64,75 \pm 5,49^{\mathrm{Ba}}$ & $40,00 \pm 4,09^{\mathrm{Bb}}$ & $28,25 \pm 3,99^{\mathrm{Bc}}$ & $24,75 \pm 3.93^{\mathrm{Bd}}$ \\
\hline TGN & $30,00 \pm 1,01^{\mathrm{Ac}}$ & $36,75 \pm 0,84^{\mathrm{Ab}}$ & $38,50 \pm 1,13^{\mathrm{Aa}}$ & $38,25 \pm 0,84^{\mathrm{Aa}}$ \\
\hline
\end{tabular}

Observa-se, no que diz respeito à umidade relativa do ar (UR), diferença entre os turnos e entre os períodos, enquanto no turno da tarde, durante o período seco, esteve abaixo do recomendado por Baeta \& Souza (1997), que é de 40 e 70\%. Com base nessa recomendação, a UR em Teresina esteve acima da faixa no período chuvoso, abaixo da faixa no período seco, a partir das 14 horas e dentro da faixa nas horas iniciais do dia até às 11 horas.

Analisando-se os dados de ITGU apresentados na Tabela 2, nota-se que existe semelhança do comportamento desses índices com a TA e TGN, tanto no período chuvoso como no período seco. Observaram-se diferenças significativas $(p<0,05)$ entre os turnos manhã e tarde. Os valores da manhã e tarde podem, no período seco, ser caracterizados como situação de alerta, pois estavam acima da zona de conforto (BAETA \& SOUSA, 1997). Comparando-se os valores de ITGU encontrados com os relatados por Silva et al. (2005), em trabalhos na região semiárida paraibana, nas épocas quente $\mathrm{e}$ seca, os valores de ITGU, tanto da manhã como da tarde, foram superiores aos relatados pelos autores citados, mostram que os animais estão sob estresse térmico no clima semiúmido de Teresina.

$\mathrm{Na}$ Tabela 3 observa-se que os caprinos Saanen e Marota, na estação chuvosa, tiveram as médias da temperatura retal crescentes do horário matutino até o horário de 14-15h, $(\mathrm{P}<0,05)$ com estabilização até as $17-18 \mathrm{~h}$. No período seco, o comportamento foi similar. 
Rev. Bras. Saúde Prod. Anim., Salvador, v.15, n.4, p.928-936 out./dez., 2014 http://www.rbspa.ufba.br ISSN 15199940

Tabela 2. Médias dos índices de temperatura e umidade (ITU) e índice do globo negro e umidade (ITGU), tomadas nos períodos chuvoso (abril e maio) e seco (outubro e novembro) e, em diferentes horários, sendo realizada no momento da coleta dos parâmetros fisiológicos, na Embrapa Meio-Norte, município de Teresina, PI, 2005

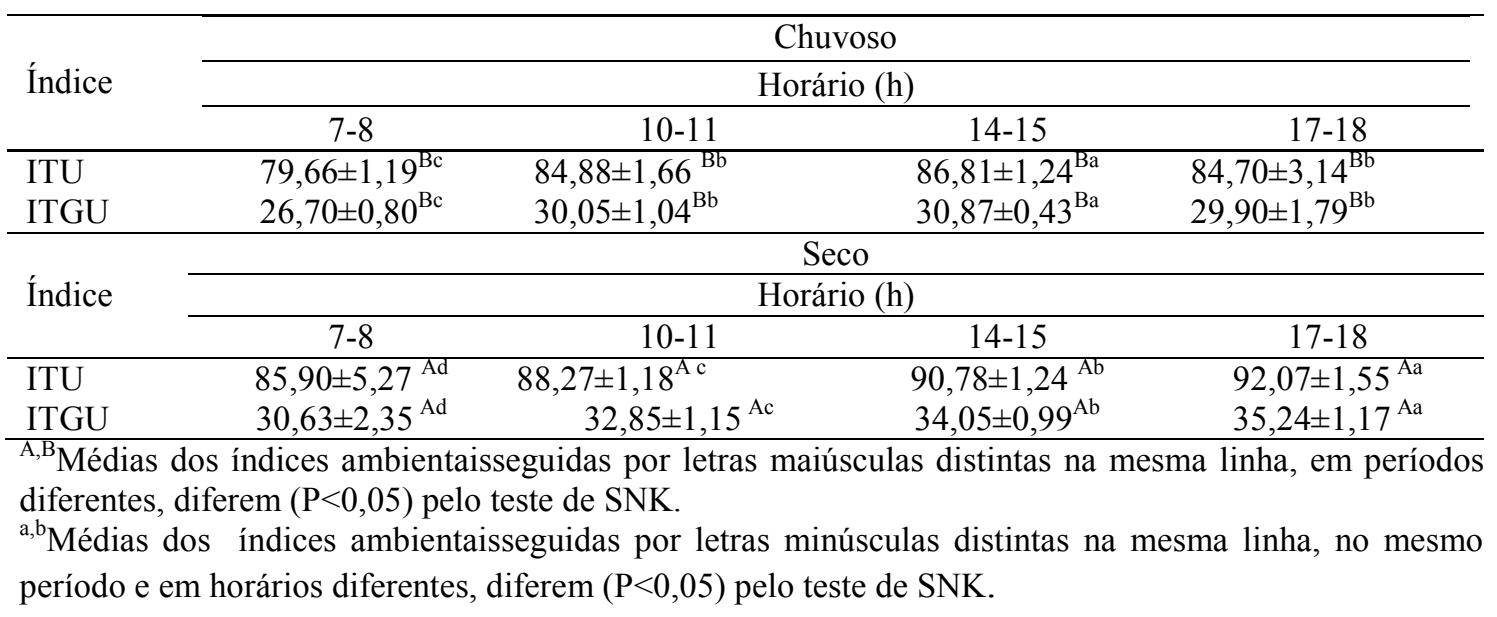

Tabela 3. Média de temperatura retal, em ${ }^{\circ} \mathrm{C}$, para animais da raça Saanen e do tipo racial Marota, nos períodos chuvoso e seco em diferentes horários de coleta, no município de Teresina, Piauí, em 2005

\begin{tabular}{lcc}
\hline \multirow{2}{*}{ Horário $(\mathrm{h})$} & \multicolumn{2}{c}{ Chuvoso } \\
\cline { 2 - 3 } & $38,28 \pm 0,45^{\mathrm{Bb} 3}$ & Marota \\
\hline $7-8$ & $38,71 \pm 0,36^{\mathrm{Ab} 2}$ & $38,57 \pm 0,48^{\mathrm{Aa} 3}$ \\
$10-11$ & $39,20^{ \pm} 0,36^{\mathrm{Aa} 1}$ & $38,90 \pm 0,45^{\mathrm{Aa} 2}$ \\
$14-15$ & $39,29 \pm 0,37^{\mathrm{Aa} 1}$ & $39,35 \pm 0,36^{\mathrm{Aa} 1}$ \\
$17-18$ & $38,87 \pm 0,55^{\mathrm{Ab}}$ & $39,34 \pm 0,32^{\mathrm{Aa} 1}$ \\
\hline Média geral & Seco & $39,04 \pm 0,52^{\mathrm{Aa}}$ \\
\hline Horário (h) & $38,57 \pm 1,46^{\mathrm{Aa} 2}$ & $38,38 \pm 0,42^{\mathrm{Aa} 3}$ \\
\hline $7-8$ & $38,74 \pm 0,37^{\mathrm{Aa} 2}$ & $38,70 \pm 0,33^{\mathrm{Aa} 2}$ \\
$10-11$ & $39,00 \pm 0,31^{\mathrm{Ba} 1}$ & $38,92 \pm 0,36^{\mathrm{Ba} 1,2}$ \\
$14-15$ & $39,06 \pm 0,40^{\mathrm{Ba} 1}$ & $39,06 \pm 0,52^{\mathrm{Ba} 1}$ \\
$17-18$ & $38,84 \pm 0,83^{\mathrm{Aa}}$ & $38,77 \pm 0,48^{\mathrm{Ba}}$ \\
\hline Média geral & & \\
A, B Médias na mesma raça em diferentes períodos seguidas de letras maiúsculas distintas diferem $(\mathrm{P}<0,05)$ \\
pelo teste de SNK. \\
a,b Médias das raças no mesmo período seguidas de letras minúsculas distintas diferem $(\mathrm{P}<0,05)$ pelo teste \\
de SNK. \\
$1,2,3$ Médias na mesma coluna, seguidas de números distintos diferem (P<0,05) pelo teste de SNK.
\end{tabular}

Resultados também semelhantes foram observados na raça Saanen, em experimento realizado no estado do Rio de Janeiro, onde foi constatada diferença entre os horários da manhã e tarde. (MEDEIROS et al., 2002; OLIVEIRA, et al., 2005) Na comparação do comportamento da TR do mesmo 
grupo nos dois períodos, observa-se nas Saanen, que na média geral não houve diferença entre períodos, enquanto as cabras Marota tiveram maior média no período chuvoso $(\mathrm{P}<0,05)$, o que leva a se suspeitar de uma maior dificuldade desse grupo nativo em perder calor em umidades mais altas.

Em relação aos valores médios do índice de temperatura e umidade (ITU), observou-se que houve diferença significativa $(p<0,05)$ entre os períodos nos respectivos horários avaliados 7-8; $10-11$; 14-15; 17-18horas. Os menores valores médios para os índices foram encontrados no horário de 7-8 horas, no período chuvoso, que diferiram dos equivalentes no período seco $(\mathrm{P}<0,05)$. Esses valores dos ITU encontrados neste experimento estão acima da zona de conforto, semelhante ao observado por Martins Junior et al. (2007b) utilizando a mesma metodologia, na mesma região com animais das raças Boer e Anglonubiano.
A frequência respiratória para caprinos é considerada normal quando apresenta valor médio de 15 movimentos respiratórios por minuto, podendo esses valores variar entre 12 e 25 movimentos por minuto e serem influenciados pelo trabalho muscular, temperatura ambiente, ingestão de alimentos, gestação, idade e tamanho do animal (REECE, 1996).

Comparando-se os valores apresentados na Tabela 4, com os encontrados por Silva et al. (2005), seja no período da manhã como no da tarde, nota-se que eles foram superiores aos encontrados por esses autores e também aos relatados por Santos et al. (2005) em caprinos mantidos à sombra. Na média global, a FR das Saanen foi significativamente superior à da Marota tanto no período seco quanto no chuvoso, denotando maior esforço para manter de perda de calor e maior estresse.

Tabela 4. Médias de frequência respiratória (mov/min), para a raça Saanen e o tipo racial Marota, nos períodos chuvoso e seco em diferentes horários de coleta, no município de Teresina, Piaúí, 2005

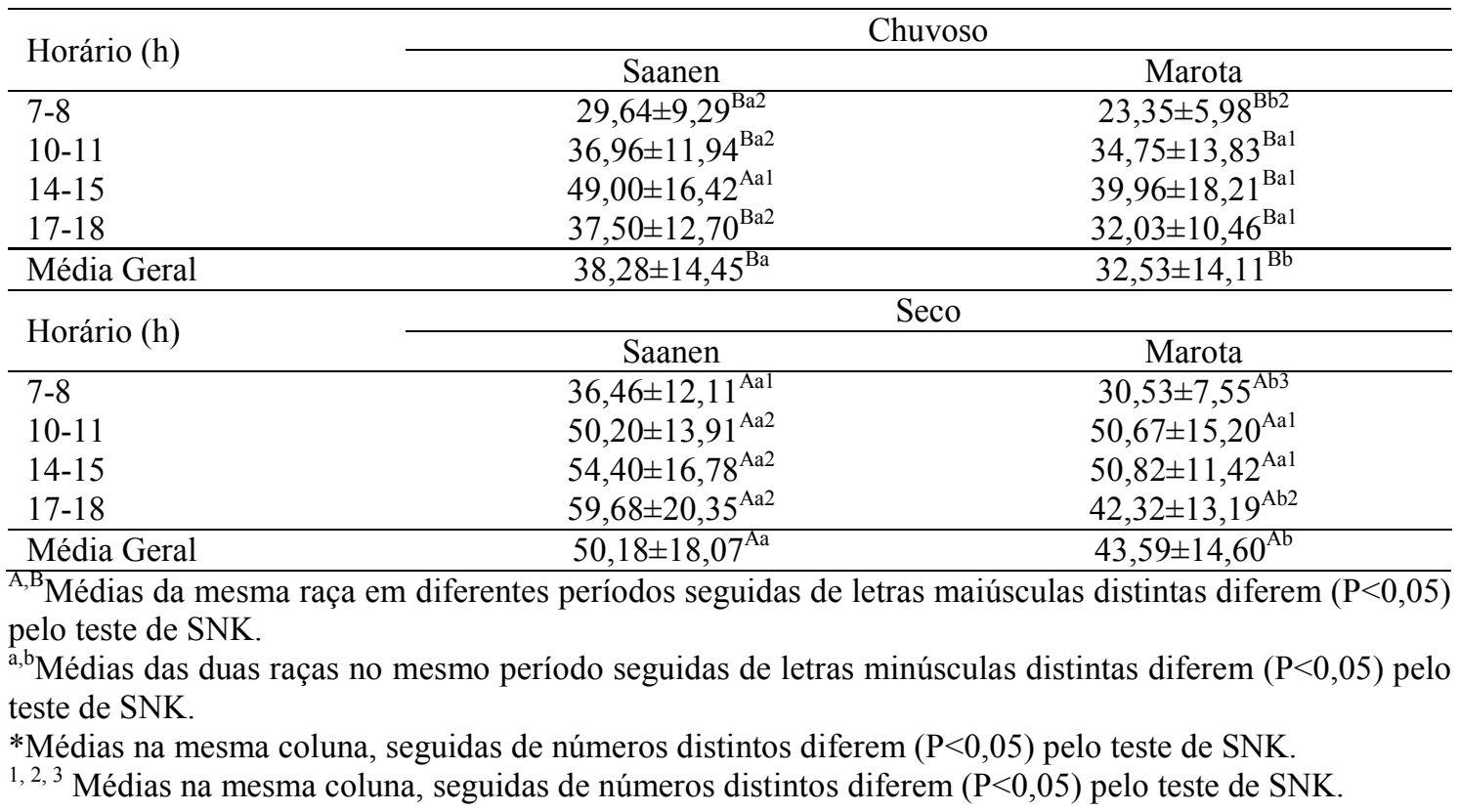


Ainda como mostra a Tabela 4, a menor média de FR (23,35 mov/min), durante o período de 7-8h da manhã do período chuvoso, foi observada na raça Marota e encontra-se dentro da faixa de normalidade para a espécie caprina (15 a $25 \mathrm{mov} / \mathrm{min})$, de acordo com Reece (1996). A média de FR do mesmo turno no período seco $(30,53 \mathrm{mov} / \mathrm{min})$ encontra-se acima da faixa de normalidade. Assim sendo, o limite de conforto para a TGN está compreendido entre 26,87 e $30^{\circ} \mathrm{C}$, para os animais Marota, porém para os Saanen, a temperatura mínima durante todo $\mathrm{o}$ período chuvoso já ensejou uma média de FR acima da normalidade (29,64 $\mathrm{mov} / \mathrm{min}$ ), fato que é realçado pela alta umidade do ar que diminui a temperatura corporal através do resfriamento das vias respiratórias, entretanto, dificulta a perda de calor por evaporação, de modo que o limite de conforto da Tgn para a raça Saanen está abaixo de $26,87^{\circ} \mathrm{C}$.
Conforme a Tabela 5, a frequência cardíaca (FC) dos animais Saanen e Marota mostrou diferença significativa $(\mathrm{P}<0,05)$ em todos os horários no período chuvoso e nenhum horário no período seco, porém, na média geral, as Saanen tiveram maior FC que as Marota $(\mathrm{P}<0,05)$ tanto no período seco quanto no chuvoso. Entre os parâmetros ambientais estudados, o único que tem maiores valores nesse primeiro horário matinal é a UR, porém no período seco a UR foi de $64 \%$, que é um patamar bastante confortável para os animais, permitindo certa evaporação e manutenção da umidade das vias respiratórias. Apesar das alterações ao longo do dia, as médias de FC estiveram dentro da zona de conforto, que está entre 70 a 80 batimentos por minuto (REECE, 1996), na maioria dos horários, com exceção dos horários 17-18horas do período chuvoso e 7-8horas no período seco, ambos para a raça Saanen.

Tabela 5. Médias de frequência cardíaca, em batimentos por minuto, para a raça Saanen e tipo racial Marota, nos períodos chuvoso e seco em diferentes horários de coleta, na Embrapa meio-norte, município de Teresina, Piauí

\begin{tabular}{|c|c|c|}
\hline \multirow{2}{*}{ Horário (h) } & \multicolumn{2}{|c|}{ Chuvoso } \\
\hline & Saanen & Marota \\
\hline $7-8$ & $79,07 \pm 9.98^{\text {Aal }}$ & $70,14 \pm 12.75^{\mathrm{Ab} 1}$ \\
\hline $10-11$ & $77,29 \pm 11.56^{\mathrm{Aa} 1}$ & $71,82 \pm 10.47^{\mathrm{Aa} 1}$ \\
\hline $14-15$ & $79,32 \pm 10.41^{\mathrm{Aa} 1}$ & $69,10 \pm 9.53^{\mathrm{Ab} 1}$ \\
\hline $17-18$ & $82,86 \pm 12.86^{\mathrm{Aa} 1}$ & $71,93 \pm 10.57^{\mathrm{Ab} 1}$ \\
\hline Média Geral & $79,63 \pm 11.29^{\mathrm{Aa}}$ & $70,75 \pm 10.81^{\mathrm{Ab}}$ \\
\hline \multirow{2}{*}{ Horário (h) } & \multicolumn{2}{|c|}{ Seco } \\
\hline & Saanen & Marota \\
\hline $07-8$ & $82,60 \pm 20.12^{\text {Aal }}$ & $73,78 \pm 18.25^{\mathrm{Aa} 1}$ \\
\hline $10-11$ & $75,58 \pm 16.41^{\mathrm{Aa} 1,2}$ & $67,42 \pm 16.43^{\mathrm{Aa} 1,2}$ \\
\hline $14-15$ & $73,46 \pm 15.48^{\mathrm{Aa} 1,2}$ & $66,39 \pm 11.72^{\mathrm{Aa} 1,2}$ \\
\hline $17-18$ & $69,40 \pm 15.45^{\mathrm{Ba} 3}$ & $59,96 \pm 12.47^{\mathrm{Ba} 2}$ \\
\hline Média Geral & $75,26 \pm 17.42^{\mathrm{Ba}}$ & $66,89 \pm 15.56^{\mathrm{Bb}}$ \\
\hline
\end{tabular}

${ }^{\mathrm{A}, \mathrm{B}}$ Médias na mesma raça em diferentes períodos seguidas de letras maiúsculas distintas diferem $(\mathrm{P}<0,05)$ pelo teste de SNK.

${ }^{\mathrm{a}, \mathrm{b}}$ Médias entre as raças no mesmo período seguida de letras minúscula distintas diferem $(\mathrm{P}<0,05)$ pelo teste de SNK.

${ }^{1,2,3}$ Médias na mesma coluna, seguidas de números distintos diferem $(\mathrm{P}<0,05)$ pelo teste de SNK. 
Rev. Bras. Saúde Prod. Anim., Salvador, v.15, n.4, p.928-936 out./dez., 2014 http://www.rbspa.ufba.br ISSN 15199940

Em síntese, quanto aos parâmetros ambientais, verificou-se que o período seco é mais estressante que o chuvoso e que o turno da tarde é mais estressante que o da manhã e dentre os esses parâmetros, observa-se que a umidade relativa do ar tem comportamento inverso ao da temperatura do ar, temperatura de globo negro e índices de temperatura e umidade, mostrando maiores valores no período chuvoso e no turno da manhã.

Quando aos parâmetros fisiológicos dos animais, observou-se que todos os animais conseguiram manter a temperatura retal dentro dos limites normais, e a frequência respiratória foi o indicador de estresse mais sensível, mostrando que os animais da raça Marota apresentaram menores valores desse parâmetro e mais próximos da zona de conforto, indicando maior adaptabilidade em relação aos da raça Saanen.

\section{REFERÊNCIAS}

AVILA, A.S. de; JÁCOME, I.M.T.D.; FACCENDA, A.; PANAZZOLO, D. M.; MULLER, E.R. Avaliação e correlação de parâmetros fisiológicos e índices bioclimáticos de vacas holandês em diferentes estações. Revista do Centro de Ciências Naturais e Exatas, v.14, n.14, p.2878-2884, 2013.

BAÊTA, F.C; SOUZA, C.F. Ambiência em edificações rurais: conforto animal. Viçosa: Universidade Federal de Viçosa, 1997. 246p.

BRASIL, L.H. de A.; WECHESLER, F.S.; BACCARI JÚNIOR, F.; GONÇALVES, H.C.; BONASSI, I.A. Efeitos do estresse térmico sobre a produção, composição química do leite e respostas termorreguladoras de cabras da raça alpina. Revista Brasileira de

Zootecnia, v.29, n.6, p.1632-1641, 2000.

MARTINS JÚNIOR, L.M.; COSTA, A.P.R.; AZEVEDO, D.M.M.R.

Respostas fisiológicas de caprinos Bôer e Anglo-Nubiano em condições climáticas de Meio-Norte do Brasil. Revista Caatinga, v.20, n.2, p.1-7, 2007a.

MARTINS JÚNIOR, L.M.; COSTA, A.P.R.; AZEVEDO, D.M.M.R.

Adaptabilidade das raças Boer e Anglonubiana às condições climáticas da Região Meio-Norte do Brasil. Archivos de Zootecnia, v.56, n.214, p.103-113, $2007 b$.

MEDEIROS, L.F.D.; VIEIRA, D.H.; QUINTANILHA, J.R. Estimativa da tolerância ao calor em caprinos. Revista Brasileira de Medicina Veterinária, v.24, n.1, p.30-35, 2002.

OLIVEIRA, F.M.M.; DANTAS, R. T.; FURTADO, D. A.; NASCIMENTO, J. W. B.; MEDEIROS, A. N. Parâmetros de conforto térmico e fisiológico de ovinos Santa Inês, sob diferentes sistemas de acondicionamento.

Construções Rurais e Ambiência, Campina Grande, p.1-13, 2005.

REECE, W.O. Fisiologia de animais domésticos. São Paulo: Roca, 1996. p.137-254.

ROCHA, D.R. da; SALLES, M.G.F.; MOURA, A. da A.A.N.; ARAÚJO, A.A. de. Índices de tolerância ao calor de vacas leiteiras no período chuvoso e seco no Ceará. Revista Acadêmica Ciências Agrárias e Ambientais, v.10, n.4, p.335-343, 2012.

SANTOS, F.C.B.; SOUSA, B.B.; ALFARO, C.E.; ACOSTA, A.A.A.; 
Rev. Bras. Saúde Prod. Anim., Salvador, v.15, n.4, p.928-936 out./dez., 2014 http://www.rbspa.ufba.br ISSN 15199940

SANTOS, J.R.S. Adaptabilidade de caprinos exóticos e naturalizados ao clima semi-árido do Nordeste Brasileiro. Ciência agrotécnica, v.29, n.1, p.142-149, 2005.

SILVA, G.A.; SOUSA, B.B.;

ALFARO, C.E.P.; SILVA, E.M.N.; AZEVEDO, S.A.; NETO, J.A.; SILVA, R.M.N. Efeito da época do ano sobre os parâmetros fisiológicos de caprinos no semi-árido. Agropecuária Científica no Semi-Árido, v.1, p.7-14, 2005.

SOUZA, D.E.; SOUZA, B.B.; SOUZA, W.H.; CEZAR, M.F.; SANTOS, J.R.S.; TAVARES, G.P. Determinação dos parâmetros fisiológicos e gradiente térmico de diferentes grupos genéticos de caprinos no semi-árido. Ciência Agrotécnica, v.29, n.1, p.177-184, 2005.

XIMENES, L.J.F.; MARTINS, G.A.; CARVALHO, J.M.M.; SOBRINHO, J.N. As ações do Banco do Nordeste do Brasil em P\&D na arte da pecuária de caprinos e ovinos no nordeste brasileiro. Fortaleza: Banco do Nordeste do Brasil, 2009. 436p.

Data de recebimento: 06/04/2014

Data de aprovação: 06/11/2014 